\title{
Numerical study of steam condensation inside a long, inclined, smooth tube at different saturation temperatures
}

\author{
S. M. A. Noori Rahim Abadi, M. Mehrabi, Josua P. Meyer* \\ Department of Mechanical and Aeronautical Engineering, University of Pretoria, \\ Pretoria, South Africa
}

*Corresponding author Email: josua.meyer@up.ac.za

Tel: +27 012420 3104, Fax: +270123625124

First author Email: ali.abadi@up.ac.za

Second author Email: mehdi.mehrabi@up.ac.za

\section{Research highlights}

I. Effect of inclination angle on the steam condensation inside the tube

II. Condensation heat transfer coefficient first increased and then decreased

III. Heat transfer coefficient decreased as the saturation temperature increased

IV. Heat transfer coefficient increased with the increase of the heat flux

V. No optimum region was found with respect to the tube inclination angle 


\begin{abstract}
In this study, the effects of the inclination angle on the heat transfer coefficients and on pressure drops were investigated numerically, during the process of development of heat condensation inside a long smooth tube, at different saturation temperatures. The simulation model included a smooth tube with a diameter of $18 \mathrm{~mm}$ and a length of 7.2 m. The imposed inclinations varied between $-60^{\circ}$ (downward flow) to $+60^{\circ}$ (upward flow). Moreover, the saturation temperatures varied between $40^{\circ} \mathrm{C}$ to $70^{\circ} \mathrm{C}$. The flow field was assumed to be three-dimensional, unsteady, and turbulent. The Volume of Fluid (VOF) multiphase flow method was utilised to solve the governing equations comprising mass, momentum, energy, and turbulence equations, along with phase change rates. The simulation results were in good agreement with the experimental data. The results showed that the condensation heat transfer coefficient first increased and then decreased along the length of the tube. Furthermore, it was noted that the condensation heat transfer coefficient and pressure drop decreased when the steam saturation temperature increased.
\end{abstract}

Keywords: Steam condensation, inclination angle, Volume of Fluid, heat transfer coefficient.

\title{
Nomenclature
}

$E \quad$ Internal energy

F $\quad$ Source term in the momentum equation

$g \quad$ Gravitational acceleration

G Mass flux

$G_{b} \quad$ Generation of turbulence kinetic energy due to buoyancy 
$h \quad$ Heat transfer coefficient

$h_{l v} \quad$ Latent heat

$k \quad$ Thermal conductivity

$k_{\mathrm{l},} k_{v} \quad$ Curvatures of liquid and vapour phases

L Tube length

$P \quad$ Pressure

$\Delta P \quad$ Pressure drop

$q^{\prime \prime} \quad$ Heat flux

$r \quad$ Tuning coefficient for condensation rate

$S_{l} \quad$ Condensation source term

$S_{v} \quad$ Evaporation source term

$S_{E} \quad$ Energy source term

$t \quad$ Time

T Temperature

$T_{\text {sat }} \quad$ Saturation temperature

u Velocity

Greek symbols

$\alpha \quad$ Volume fraction

$\mu \quad$ Molecular viscosity

$\tau \quad$ Shear tension

$\rho \quad$ Density

$\kappa \quad$ Turbulent kinetic energy

$\varepsilon \quad$ Turbulent dissipation rate

$\beta \quad$ Inclination angle

$r \quad$ Tuning coefficient in condensation source term 
$\sigma \quad$ Surface tension

$\varphi \quad$ Rotation angle

$\omega \quad$ Angular velocity

$\bar{\Omega}_{i j} \quad$ Mean rate of rotation tensor

\section{Subscripts}

$\begin{array}{ll}\text { ave } & \text { Average } \\ \text { eff } & \text { Effective } \\ l & \text { Liquid } \\ L & \text { Laminar } \\ m & \text { Mixture } \\ \text { sat } & \text { Saturation } \\ t & \text { Turbulent } \\ v & \text { Vapour } \\ \text { wall } & \text { Tube wall }\end{array}$

\section{Introduction}

Condensation inside tubes can be found in the air-conditioning, refrigeration, automotive, and processing industries. For designs applicable to these industries, an accurate and in-depth understanding of the flow patterns and the heat transfer phenomenon is of major importance [1-5]. Many applications involve condensation inside inclined tubes such as, in A-frame steam condensers used in air-cooled, power generation plants, some rooftop air-cooled refrigeration systems, and also in the low temperature multi-effect evaporation in desalination industry [6]. However, a literature review by Lips and Meyer [7], showed that very limited work was conducted on condensation inside inclined tubes. 
Mohseni et al. [8] conducted an experimental investigation to study the heat transfer and flow patterns inside an inclined smooth tube during condensation. They found that the inclination angle had a significant effect on the heat transfer coefficients and on flow patterns, particularly at low vapour qualities and mass fluxes. They also captured eight different flow regimes during condensation inside the tube at different tube inclination angles.

Nada and Hussein [9] presented a semi-empirical correlation to predict the heat transfer coefficient inside an inclined smooth tube during condensation. They found that the Nusselt number increased as the temperature difference decreased, while the tube inclination angle increased. Their analytical results showed a good agreement with experimental data for vertical and horizontal tubes, but the deviation increased as the inclination angle increased. This result shows a lack of understanding of the effects of the inclination angle on condensation.

Lips and Meyer [10-13] experimentally studied the effect of the inclination angle on the condensation inside a smooth tube. The inclination angles varied from the vertical downward, to the horizontal, and to the vertical upward directions. They studied the effect of tube inclination angles on the pressure drop, void fraction, and heat transfer coefficient, and also captured the flow regime at the tube outlet. Their most important result was that the optimum heat transfer coefficients occurred at a downward inclination angle in the range of $15^{\circ}-30^{\circ}$, and specifically at mass fluxes lower than approximately $200 \mathrm{~kg} / \mathrm{m}^{2} \mathrm{~s}$. 
Xu et al. [14] studied gas-liquid, two-phase flows inside an inclined tube. They focussed on the influence of the liquid phase properties on flow patterns, void fractions, and pressure drops. They used both Newtonian and non-Newtonian fluids for the liquid phase. They concluded that the properties of non-Newtonian fluids had no significant effect on the flow patterns in horizontal and near-horizontal flows. They also found that the non-Newtonian features of the liquid phase had a considerable effect on the void fraction. Furthermore, they presented predictive models for the calculation of void fractions and pressure drops for the stratified flow of gas and non-Newtonian liquids.

Shah [15] conducted a literature review on heat transfer during condensation in an inclined tube. He proposed a method for the calculation of heat transfer coefficients inside inclined tubes during condensation. The method elicited a mean absolute deviation of $15.7 \%$ with the use of the available database.

In addition to various prior publications on the condensation of refrigerants, many researchers considered steam as the working fluid in their investigations. Caruso et al. [16] experimentally studied condensation of steam-air mixed with gas inside inclined tubes at four inclination angles. They found that the heat transfer coefficients at inclination angles of $15^{\circ}$ and $30^{\circ}$ were higher than those at $7^{\circ}$ and $45^{\circ}$. They also developed a correlation that predicted the heat transfer coefficients as a function of the inclination angle.

Wang et al. [17] investigated the steam condensation inside a long, $8 \mathrm{~m}$, horizontal smooth tube. They studied the effects of saturation temperature, steam mass flow rate, and temperature differences, between steam and cooling water on the condensation 
heat transfer coefficient. They found that the condensation heat transfer coefficient increased first and then decreased along the flow direction. Moreover, their results showed that the heat transfer coefficient also increased with saturation temperature, and decreased with condensation temperature differences.

Wang and Du [18] studied steam condensation in long smooth tubes experimentally and analytically. They considered different parameters in their investigation, such as steam mass flow rate, tube diameter, and inclination angle. Their results showed that gravity decreased the condensation heat transfer coefficient in small/mini tubes. It was also found that the inclination angle affected the condensation heat transfer mainly by stratifying the fluids, and by thinning the liquid film.

In addition to prior publications on the condensation of pure steam, some researchers worked on the condensation of steam inside a smooth tube by considering the effect of non-condensable gases [19-22].

Vyskocil et al. [23] developed a CFD model to study the effect of non-condensable gas on the heat transfer coefficient during steam condensation inside a vessel. They used the FLUENT commercial package solver and claimed that their proposed code is applicable for both compressible and incompressible flows of air-steam mixtures with additional non-condensable gases. Their condensation model was also examined on CONAN experiments with air-steam flow in a vertical channel with one cooled wall. Satisfactory results were elicited. However, the model suffered from various parameters that were over-simplified. 
Ren et al. [24] studied the effect of air as a non-condensable gas on the condensation heat transfer coefficient and the flow regime inside a smooth horizontal tube. They considered the effects of various parameters in their experiments, such as the inlet noncondensable gas mass fraction, inlet gas mixture mass flux, and inlet pressure. They found that the heat transfer coefficient decreased as the non-condensable gas fraction increased. Their results also showed that the increase in the inlet mass flux would increase the heat transfer coefficient. They also proposed two correlations for the condensation heat transfer coefficient for stratified flow and annular flow regimes, based on the modified Froude number.

Although there are several experimental and numerical works on the condensation of the refrigerant and steam inside vertical and horizontal tubes [25-28], to the best of our knowledge, there has been no prior published numerical work in which the effects of saturation temperature and tube inclination angle on the condensation of steam inside tubes have been investigated. Furthermore in this study we aimed to consider very low mass fluxes in which a complete condensation happened. This type of condensing flows are widely seen in many applications particularly in in A-frame steam condensers and low temperature multi-effect evaporation in desalination industry. It is therefore the purpose of this study to numerically investigate the condensation of low-pressure steam in a long, smooth tube. The effects of various parameters, such as the inclination angle of the tube, saturation temperature, and steam mass flow rate, on the heat transfer coefficient, pressure drop, and flow regime are studied. 


\section{Mathematical formulation}

\subsection{Volume of fluid model}

The volume of fluid (VOF) multi-phase flow formulation $[22,29]$ was used for the simulation of the phenomenon of condensation inside an inclined tube. In the VOF model, the sum of the volume fractions of each phase in a computational cell is unity.

$\alpha_{l}+\alpha_{v}=1$,

where $\alpha$ is the volume fraction, and indices $l$ and $v$ represent the liquid and vapour phases, respectively.

The continuity equations for the volume fractions of each phase are presented as

$$
\begin{aligned}
& \frac{\partial \alpha_{v}}{\partial t}+\nabla \cdot\left(\vec{u} \alpha_{v}\right)=\frac{S_{v}}{\rho_{v}} \text { and } \\
& \frac{\partial \alpha_{l}}{\partial t}+\nabla .\left(\vec{u} \alpha_{l}\right)=\frac{S_{l}}{\rho_{l}},
\end{aligned}
$$

where $u, \rho$, and $t$, denote velocity, density, and time, respectively. Parameter $S$ is the source term pertaining to phase changes. As the velocity difference between each phase is neglected in the VOF method, only one momentum equation is presented as follows:

$$
\frac{\partial\left(\rho_{m} \vec{u}\right)}{\partial t}+\nabla \cdot\left(\rho_{m} \vec{u} \vec{u}\right)=-\nabla P+\nabla \cdot\left[\mu_{m, e f f}\left(\nabla \vec{u}+(\nabla \vec{u})^{T}\right)\right]+\rho_{m} \vec{g}+\vec{F}_{\sigma} \text {, }
$$


where $\mu_{e f f}, P, g$, and $F_{\sigma}$, are the effective viscosity, pressure, gravitational acceleration, and surface tension force, respectively. The energy equation is also defined as

$$
\frac{\partial\left(\rho_{m} E\right)}{\partial t}+\nabla \cdot\left[\vec{u}\left(\rho_{m} E+P\right)\right]=\nabla \cdot\left(k_{m, e f f} \nabla T\right)+S_{E}
$$

where $T, E$, and $k_{e f f}$, are the temperature, internal energy, and effective thermal conductivity, respectively. In the VOF method, the average phase properties are used and are defined as

$$
\begin{aligned}
& k_{m}=\alpha_{l} k_{l}+\alpha_{v} k_{v} \\
& \rho_{m}=\alpha_{l} \rho_{l}+\alpha_{v} \rho_{v} . \\
& \mu_{m}=\alpha_{l} \mu_{l}+\alpha_{v} \mu_{v}
\end{aligned}
$$

Furthermore, the effective parameters $\mu_{\text {eff }}$ and $k_{\text {eff }}$ are defined as follows:

$$
\begin{aligned}
& \mu_{\text {eff }}=\mu_{L}+\mu_{t} \\
& k_{\text {eff }}=k_{L}+k_{t}
\end{aligned},
$$

where the indices $L$ and $t$ stand for laminar and turbulent flows, respectively.

The surface tension force was computed by the CSF model for the cells containing the vapour-liquid interface [30]. The continuum surface force (CSF) model was implemented such that the addition of surface tension to the VOF calculation resulted in a source term in the momentum equation as follows: 


$$
F_{\sigma}=\sigma \frac{\alpha_{l} \rho_{l} k_{v} \nabla \alpha_{v}+\alpha_{v} \rho_{v} k_{l} \nabla \alpha_{l}}{\frac{1}{2}\left(\rho_{v}+\rho_{l}\right)}
$$

where $\sigma$ is the water surface tension. The curvatures of the liquid and vapour phase were defined as

$$
k_{l}=\nabla \cdot \frac{\nabla \alpha_{l}}{\left|\nabla \alpha_{l}\right|}, \quad k_{v}=\nabla \cdot \frac{\nabla \alpha_{v}}{\left|\nabla \alpha_{v}\right|} .
$$

\subsection{Turbulence modelling}

For modelling turbulence, the two-equation turbulence model, realizable $\kappa-\varepsilon$, is applied. The equations of turbulence energy and dissipation rate are expressed as follows [31]:

$$
\begin{aligned}
& \frac{\partial\left(\rho_{m} \kappa\right)}{\partial t}+\nabla \cdot\left(\rho_{m} \vec{u} \kappa\right)=\nabla \cdot\left[\left(\mu_{L, m}+\frac{\mu_{t, m}}{\sigma_{\kappa}}\right) \nabla \kappa\right]+\left[\mu_{t, m}\left(\nabla \vec{u}+(\nabla \vec{u})^{T}\right): \nabla \cdot \vec{u}\right]-\rho_{m} \varepsilon+G_{b} . \\
& \frac{\partial\left(\rho_{m} \varepsilon\right)}{\partial t}+\nabla \cdot\left(\rho_{m} \vec{u} \varepsilon\right)=\nabla \cdot\left[\left(\mu_{L, m}+\frac{\mu_{t, m}}{\sigma_{\varepsilon}}\right) \nabla \varepsilon\right]+\rho_{m} C_{1} S \varepsilon-\rho_{m} C_{2} \frac{\varepsilon^{2}}{\kappa+\sqrt{v \varepsilon}}+C_{1 \varepsilon} C_{3 \varepsilon} \frac{\varepsilon}{\kappa} G_{b} .
\end{aligned}
$$

where $\kappa, \varepsilon$, and $G_{b}$ are the turbulent kinetic energy and turbulent energy dissipation rate, and the generation of turbulence kinetic energy due to buoyancy, respectively. The turbulent viscosity, $\mu_{t}$, relates to the turbulence energy, $\kappa$, and dissipation rate, $\varepsilon$, such that 
$\mu_{m, \mathrm{t}}=C_{\mu} \frac{\rho_{m} \kappa^{2}}{\varepsilon}$

where $C_{\mu}$ is a function of various parameters calculated as follows:

$$
\begin{aligned}
& C_{\mu}=\frac{1}{A_{0}+A_{s} \frac{\kappa U^{*}}{\varepsilon}}, U^{*}=\sqrt{S_{i j} S_{i j}+\widehat{\Omega}_{i j} \widehat{\Omega}_{i j}}, \widehat{\Omega}_{i j}=\Omega_{i j}-2 \varepsilon_{i j} \omega_{k}, \\
& \Omega_{i j}=\bar{\Omega}_{i j}-\varepsilon_{i j} \omega_{k}
\end{aligned}
$$

where, $\bar{\Omega}_{i j}$ is the mean rate of rotation tensor in a moving reference frame with an angular velocity of, $\omega_{k}$. The other constants and parameters are defined as:

$$
\begin{aligned}
& A_{0}=4.04, A_{s}=\sqrt{6} \cos \varphi, \varphi=\frac{1}{3} \cos ^{-1}(\sqrt{6} W), W=\frac{S_{i j} S_{j k} S_{k i}}{\tilde{S}^{3}}, \\
& \tilde{S}=\sqrt{S_{i j} S_{i j}}, S_{i j}=0.5\left(\frac{\partial \vec{u}_{i}}{\partial x_{j}}+\frac{\partial \vec{u}_{j}}{\partial x_{i}}\right) \\
& C_{1}=\max \left[0.43, \frac{\eta}{\eta+5}\right], \eta=S \frac{\kappa}{\varepsilon}, S=\sqrt{2 S_{i j} S_{i j}}, \\
& C_{2}=1.92, C_{1 \varepsilon}=1.44, C_{3 \varepsilon}=\tanh \left|\frac{v}{u}\right|, \sigma_{k}=1.0, \sigma_{\varepsilon}=1.2
\end{aligned}
$$

Further details on the constants can be found in [31]. 


\subsection{Phase change source terms}

In this study, the effect of the phase phenomenon was considered based on the source terms in the governing equations. The mass transfer source terms can be expressed as $[32,33]$

$$
\begin{aligned}
& S_{l}=r_{l} \alpha_{l} \rho_{l} \frac{T-T_{\text {sat }}}{T_{\text {sat }}} \quad T \geq T_{\text {sat }} \text { and } \\
& S_{v}=r_{v} \alpha_{v} \rho_{v} \frac{T_{\text {sat }}-T}{T_{\text {sat }}} \quad T<T_{\text {sat }},
\end{aligned}
$$

where $T_{\text {sat }}$ is the saturation temperature of the working fluid. The coefficients $r_{l}$ and $r_{v}$ were tuned to fit the experimental data. It should be noticed that only one of these equations, depending on the specified condition, is used for each computational cell. Therefore the relation is always holds within the each cell during the simulations. The main purpose of introducing the parameter $r$ is to maintain the saturation condition at the liquid-vapour interface. Moreover properly determine this parameter leads to the correct values of mass transfer rate and condensation heat transfer coefficient. The coefficient $r$ may vary from 0.1 to $10^{7}$ [34-38], depending on many factors, including, but not limited to, mesh size, phase-change phenomenon, mass flow rate, computational time step size and experimental conditions. It should be noted that excessively small values of the coefficient, $r$, lead to a significant deviation between the interfacial and saturation temperature. However, very large values of $r$ cause numerical convergence problems. In the present study, the values of $r_{l}$ and $r_{v}$ were considered to be between to 7000 to $15000 \mathrm{~s}^{-1}$ based on the operating conditions, as it led to the lowest deviations compared to the experimental data. Moreover, by using this value the differences 
between the interface temperature and saturation temperature are observed to be less than $0.7^{\circ} \mathrm{C}$. The relevant source term in the energy equation is defined as follows:

$$
S_{E}=-S_{l} h_{l v},
$$

where $h_{l v}$ is the latent heat of condensation. The aforementioned source terms expressed in terms of the mass, momentum, and energy equations, were implemented in the solver via a 'User Defined Function'.

The average heat transfer coefficient along the tube was calculated as follows:

$$
h_{\text {ave }}=\frac{q^{\prime \prime}}{T_{\text {sat }}-T_{\text {wall,ave }}},
$$

where $T_{\text {wall,ave }}$ and $q$ " are the average tube wall temperature and heat flux, respectively.

The following assumptions were used for the simulations:

1. The flow regimes were stratified or annular. Therefore, it is always possible to capture a certain two-phase interface using the VOF model

2. The flow field was considered three-dimensional, unsteady, and turbulent

3. The liquid phase, heavier phase, was assumed as the primary phase and the vapour phase was the secondary phase. The ANSYS FLUENT software solves the volume fraction equation only for the secondary phase and uses Eq. 1 to determine the volume fraction of the primary phase.

4. The velocity difference between the liquid and vapour phases was neglected 
5. The properties of each phase were assumed to be functions of the temperature as presented in Table 1 [39].

6. The interface temperature was assumed to be at the saturation temperature

Table 1. Variations of water liquid and vapour thermal properties with respect to the temperature [39].

\begin{tabular}{|c|c|c|c|c|c|c|c|}
\hline Property & $\alpha_{0}$ & $\alpha_{1}$ & $\alpha_{2}$ & $\boldsymbol{\alpha}_{3}$ & $\alpha_{4}$ & $\alpha_{5}$ & $\begin{array}{l}\text { Error } \\
(\%)\end{array}$ \\
\hline$P\left(10^{5} \mathrm{~Pa}\right)$ & -5.0945 & $7.2280 \times 10^{-2}$ & $-2.8625 \times 10^{-4}$ & $9.2341 \times 10^{-7}$ & $-2.0295 \times 10^{-9}$ & $2.1645 \times 10^{-12}$ & 0.01 \\
\hline$h_{l v}(\mathbf{k J} / \mathbf{k g})$ & 7.8201 & $-5.8906 \times 10^{-4}$ & $-9.1355 \times 10^{-6}$ & $8.4738 \times 10^{-8}$ & $\begin{array}{c}-3.9635 \times 10^{-} \\
10\end{array}$ & $5.9150 \times 10^{-13}$ & 0.05 \\
\hline$\rho_{I}\left(\mathrm{~kg} / \mathrm{m}^{3}\right)$ & 6.9094 & $-2.0146 \times 10^{-5}$ & $-5.9868 \times 10^{-6}$ & $2.5921 \times 10^{-8}$ & $\begin{array}{c}-9.3244 \times 10^{-} \\
11\end{array}$ & $1.2103 \times 10^{-13}$ & 0.02 \\
\hline$\rho_{v}\left(\mathrm{~kg} / \mathrm{m}^{3}\right)$ & -5.3225 & $6.8366 \times 10^{-2}$ & $-2.7243 \times 10^{-4}$ & $8.4522 \times 10^{-7}$ & $-1.6558 \times 10^{-9}$ & $1.5514 \times 10^{-12}$ & 0.01 \\
\hline$\mu_{l}\left(10^{-7} \mathrm{Ns} / \mathrm{m}^{2}\right)$ & 9.7620 & $-3.1154 \times 10^{-2}$ & $2.0029 \times 10^{-4}$ & $-9.5815 \times 10^{-7}$ & $2.7772 \times 10^{-9}$ & $\begin{array}{c}-3.5075 \times 10^{-} \\
12\end{array}$ & 0.02 \\
\hline $\begin{array}{l}\mu_{V}\left(10^{-7}\right. \\
\left.\mathrm{Ns} / \mathrm{m}^{2}\right)\end{array}$ & 4.3995 & $3.8789 \times 10^{-3}$ & $2.1181 \times 10^{-5}$ & $-3.4406 \times 10^{-7}$ & $1.6730 \times 10^{-9}$ & $\begin{array}{c}-2.8030 \times 10^{-} \\
12\end{array}$ & 0.04 \\
\hline$k_{I}(\mathrm{~W} / \mathrm{mK})$ & -0.56528 & $3.1743 \times 10^{-3}$ & $-1.4392 \times 10^{-5}$ & $-1.3224 \times 10^{-8}$ & $2.5534 \times 10^{-10}$ & $\begin{array}{c}-6.4454 \times 10^{-} \\
13\end{array}$ & 0.04 \\
\hline$k_{v}(\mathrm{~W} / \mathrm{mK})$ & -4.0406 & $3.2288 \times 10^{-3}$ & $5.3383 \times 10^{-6}$ & $-6.7139 \times 10^{-8}$ & $4.0967 \times 10^{-10}$ & $\begin{array}{c}-6.9579 \times 10^{-} \\
13\end{array}$ & 0.07 \\
\hline$\sigma\left(10^{-3} \mathrm{~N} / \mathrm{m}\right)$ & 4.3438 & $-3.0664 \times 10^{-3}$ & $2.0743 \times 10^{-5}$ & $-2.5499 \times 10^{-7}$ & $1.0377 \times 10^{-9}$ & $\begin{array}{c}-1.7156 \times 10 \\
13\end{array}$ & 0.03 \\
\hline$c_{p, I}(\mathrm{~kJ} / \mathrm{kgK})$ & 1.4338 & $-2.2638 \times 10^{-4}$ & $4.2819 \times 10^{-6}$ & $-2.7411 \times 10^{-8}$ & $1.4699 \times 10^{-10}$ & $\begin{array}{c}-2.2589 \times 10^{-} \\
13\end{array}$ & 0.01 \\
\hline$c_{p, v}(\mathrm{~kJ} / \mathrm{kgK})$ & 0.62084 & $3.1420 \times 10^{-4}$ & $1.6110 \times 10^{-6}$ & $4.0156 \times 10^{-8}$ & $3.4841 \times 10^{-11}$ & $\begin{array}{c}-2.0709 \times 10^{-} \\
13\end{array}$ & 0.01 \\
\hline
\end{tabular}

7. $\operatorname{Ln}($ Property $)=\alpha_{0}+\alpha_{1} T+\alpha_{2} T^{2}+\alpha_{3} T^{3}+\alpha_{4} T^{4}+\alpha_{5} T^{5}\left(20<\mathrm{T}<200{ }^{\circ} \mathrm{C}\right)$

\subsection{Boundary conditions and solution method}

Fig. 1 shows the computational domain of the present numerical study. The computational domain was an 18-mm inner diameter circular smooth tube with a length of $7200 \mathrm{~mm}$. The tube has already been used by Wang et al. [17] for the experimental study of steam condensation. The following boundary conditions were assumed for all the simulations: 
1. Inlet: The mass flux and temperature of the saturated pure vapour were specified.

2. Outlet: The static gauge pressure was $0 \mathrm{~Pa}$.

3. Wall: A constant heat flux of 7,10 , and $13 \mathrm{~kW} / \mathrm{m}^{2}$, on the tube surface.

4. Saturation temperatures were $40,50,60$, and $70{ }^{\circ} \mathrm{C}$, at the exit boundary of the tube. As the tube length is excessively long and equal to $7 \mathrm{~m}$, the saturation temperature of the steam decreases along the length of the tube. Therefore, the variations of saturation temperatures along the tube length were taken into account for the simulations, based on the experimental data of Wang et al. [17].

5. The saturation temperatures at the inlet boundary were determined with the help of the experimental measurements of Wang et al. [17]. The first approximation was provided according the specified operating condition and corresponding experimental data, then it was modified during the solution process. As the pressure drop was determined by solving the governing equations the corresponding pressure and saturation temperature at the inlet boundary were calculated. This procedure continued until the correct values of the condensation heat transfer coefficient and pressure drop were achieved.

6. The no-slip condition was assumed to be valid at the tube wall, and the contact angle between the liquid and wall was set to $80^{\circ}$ [40].

7. The tube orientations varied between $-60^{\circ}$ to $60^{\circ}$. The selection of this range of tube inclination angles was based on the conclusions of prior experimental works by Lips and Meyer $[10,11]$ and Olivier et al. [6], that reported that the optimum inclination angle would range between $-30^{\circ}$ to $0^{\circ}$ for the condensation of R134a inside a tube. They also observed that the minimum heat transfer 
coefficient would be at an inclination angle of $+90^{\circ}$ or $-90^{\circ}$. Therefore, the ranges of $-90^{\circ}<\beta<-60^{\circ}$ and $60^{\circ}<\beta<90^{\circ}$ were not considered in this study.

\section{8.}



9. (a)

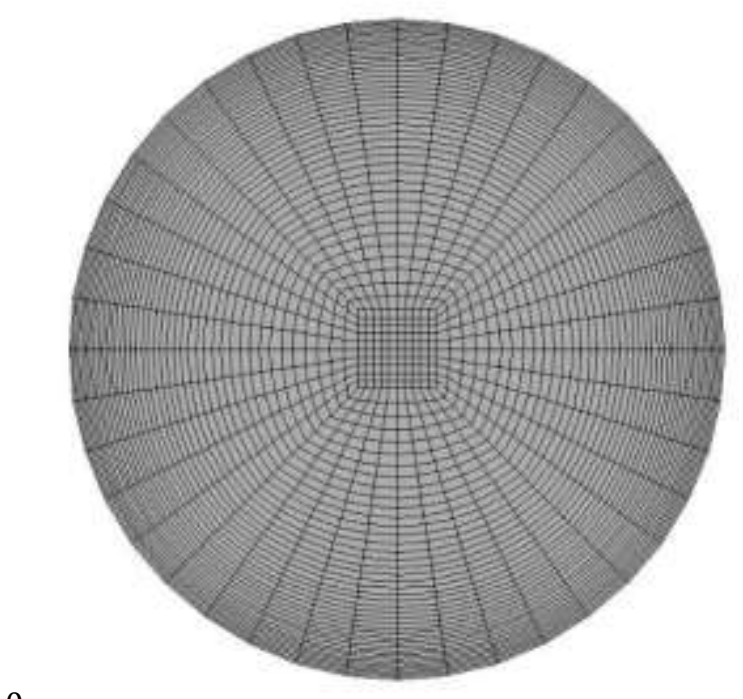

10.

11. (b)

Fig. 1. (a) Model schematic, and (b) computational grid.

Furthermore, the total volume of the tube was filled with vapour, and the temperature in each cell was equal to the saturation temperature at the initial conditions. 
The governing equations were solved with the commercial software package ANSYS FLUENT 17.1. The pressure-velocity coupling was achieved using the pressure implicit with splitting of operator algorithm (PISO). To obtain a stable solution, all the convective fluxes were approximated by a second-order upwind method, while the diffusive fluxes were discretised using central differencing. To capture the liquid/vapour interphase, the Geo-Reconstruction scheme was utilised [41]. Furthermore, the convergence criterion was set to $10^{-5}$ for the residual of each parameter. A time-step size of $10^{-4} \mathrm{~s}$ was used for all the simulations.

\section{Results and discussion}

\subsection{Validation of numerical method}

To obtain an optimal computational mesh, four grid sizes in the range of 322000 to 1425000 cells were investigated to determine the appropriate grid resolution, as shown in Fig. 2. The presented results are for the condition of $G=6.6 \mathrm{~kg} / \mathrm{m}^{2} \mathrm{~s}, \beta=0^{\circ}, q^{\prime \prime}=7$ $\mathrm{kW} / \mathrm{m}^{2}$, and for a saturation temperature of $40^{\circ} \mathrm{C}$. All grids complied with the enhanced wall treatment requirement for the dimensionless wall coordinate $y^{+}$orthogonal to the wall, which imposed the condition such that $y^{+}<2$ in the first grid point next to the wall. In the simulations, $y^{+}$values were set in the range of $1-2$. Therefore the enhanced wall treatment was used in order to properly capture the laminar sublayer as well as the turbulent region within the boundary layer. This model applies a blending function to sweep all regions from the laminar zone to the turbulent zone. The grid results showed that the deviations between each grid were within the ranges of the uncertainties of the experimental data, which were approximately 4\%. Based on the grid results, the grid with 926000 cells was selected for this study as it provided an acceptable compromise between accuracy and simulation time. 


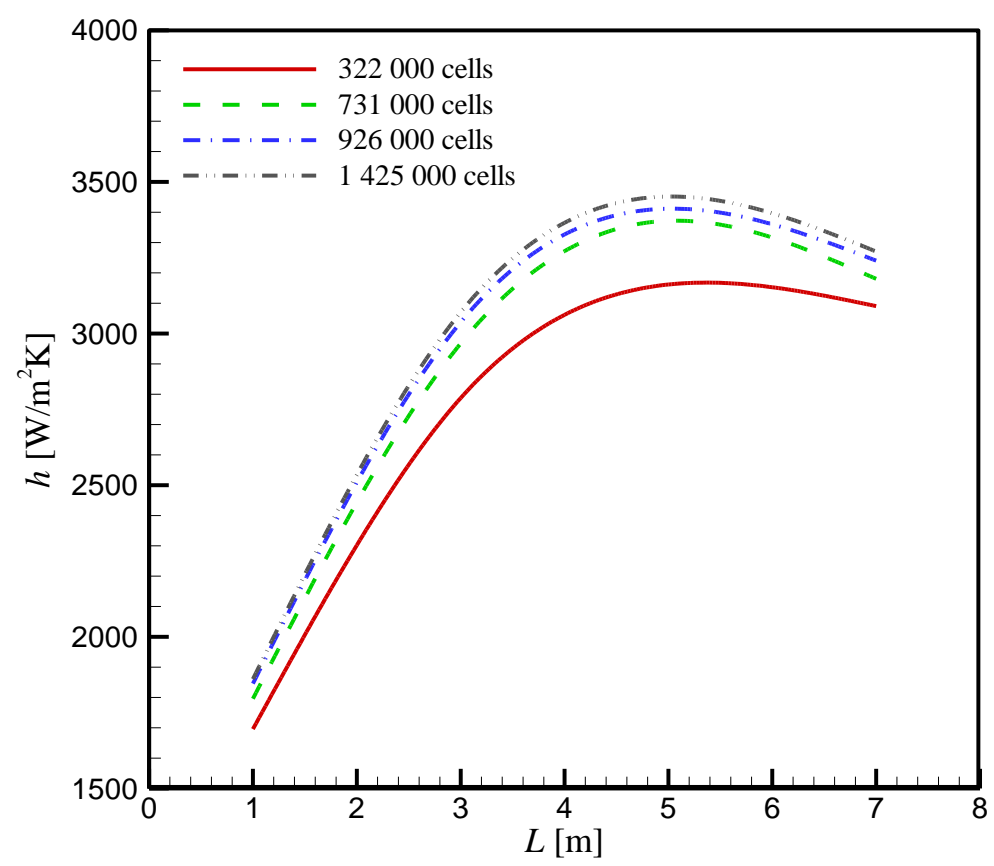

Fig. 2. Effect of grid size on the condensation heat transfer coefficient along the tube.

Fig. 3 shows the comparison between the present numerical results and the experimental data of Wang et al. [17]. The presented results are for the horizontal tube at the operating condition of $G=6.6 \mathrm{~kg} / \mathrm{m}^{2} \mathrm{~s}$, and at the two saturation temperatures of $50^{\circ} \mathrm{C}$ and $70^{\circ} \mathrm{C}$. In this case, the imposed negative heat flux on the tube wall varied from $400 \mathrm{~W} / \mathrm{m}$ to $700 \mathrm{~W} / \mathrm{m}$ along the length of the tube [17]. The tube was divided into four sections, and the reported values for the heat transfer coefficients were the average values of each section. The plots clearly show that the present numerical method is capable of predicting the condensation heat transfer coefficient inside the tube. The maximum deviation between the numerical results and experimental data is $5 \%$. 


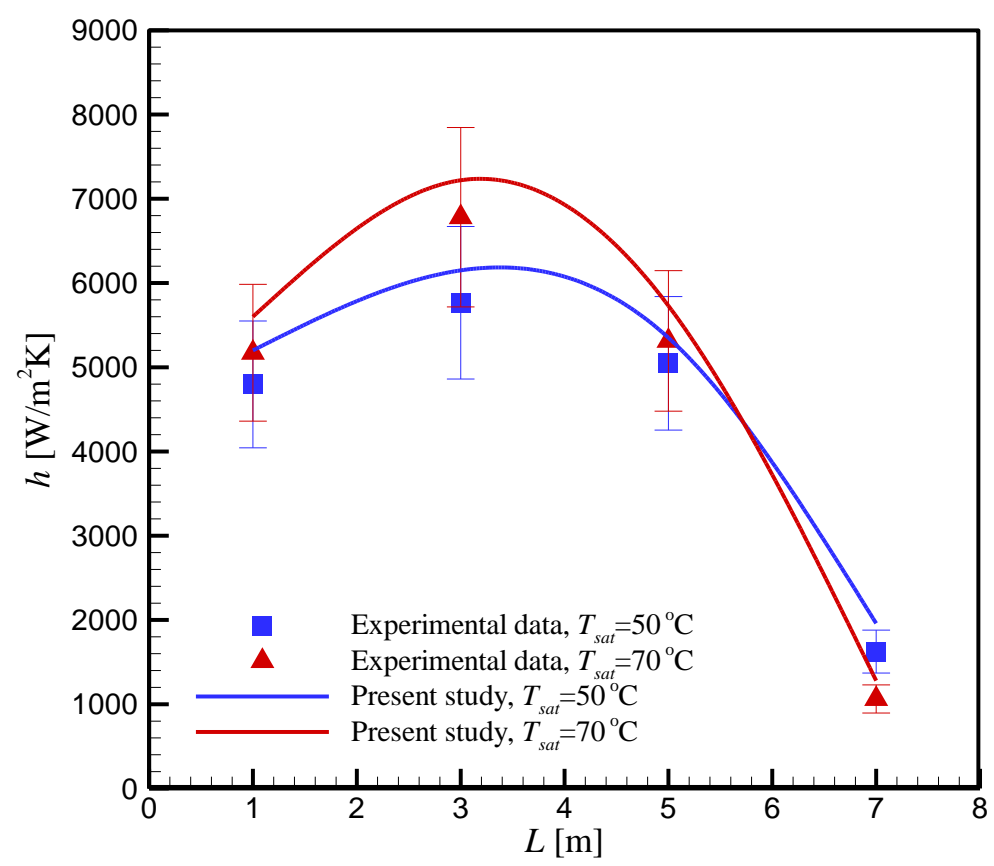

Fig. 3. Comparison between the numerical results of this study and the experimental data from Wang et al. [17] for the condensation heat transfer coefficient along the horizontal tube.

\subsection{Effect of saturation temperature}

Fig. 4 shows the variations of the condensation heat transfer coefficient along the tube length at $G=6.6 \mathrm{~kg} / \mathrm{m}^{2} \mathrm{~s}$ and $q^{\prime \prime}=7 \mathrm{~kW} / \mathrm{m}^{2}$ for different saturation temperatures and tube inclination angles. As it can be seen, the condensation heat transfer coefficient increases first, and then decreases along the tube. As the tube length is excessively long, the saturation temperature decreases along the tube owing to the high pressure drop. At the entrance region of the tube, the decrease in the wall temperature is smaller than that of the saturation temperature, due to the high condensation heat transfer coefficient. Therefore, at the entrance region of the tube, the condensation heat transfer coefficient increases, as the imposed heat flux on the tube wall is maintained constant. Regarding condensation, as its thickness increases along the tube, the liquid film acts as 




(a)

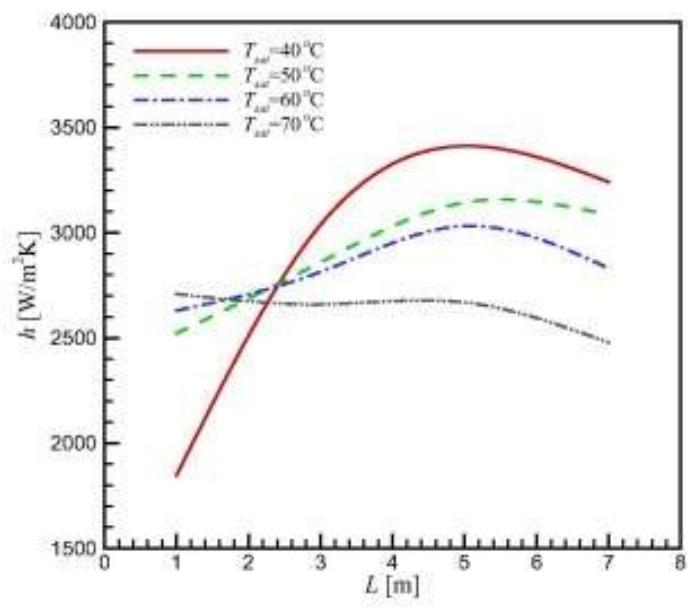

(c)

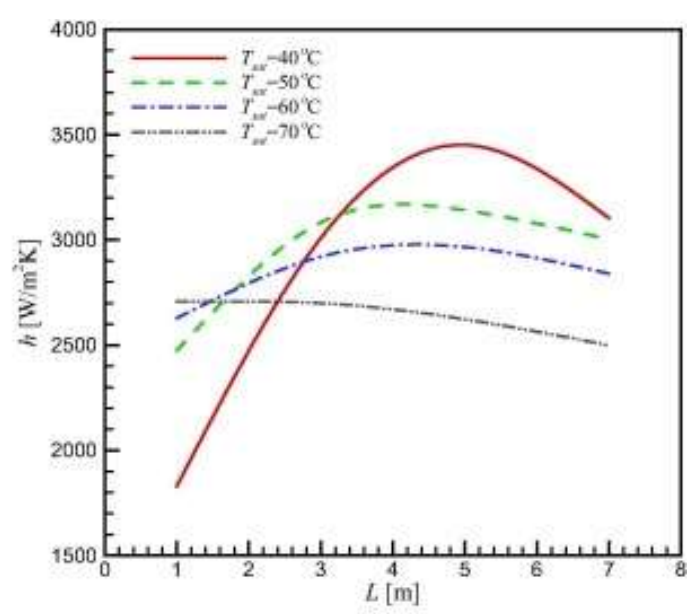

(b)

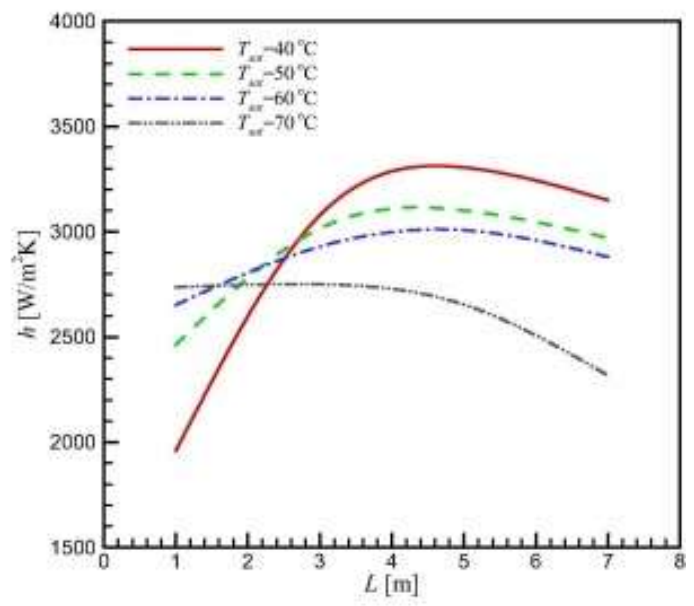

(d)

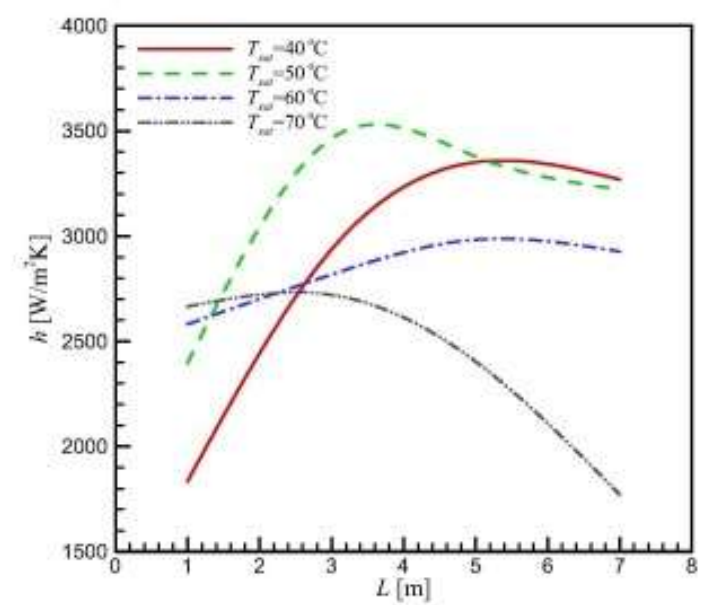

(e)

Fig. 4. Effect of saturation temperatures on the heat transfer coefficient along the tube for $G=6.6 \mathrm{~kg} / \mathrm{m}^{2} \mathrm{~s}$ and $q^{\prime \prime}=7 \mathrm{~kW} / \mathrm{m}^{2}$. (a) $\beta=-60^{\circ}$, (b) $\beta=-30^{\circ}$, (c) $\beta=0^{\circ}$, (d) $\beta=+30^{\circ}$, and (e) $\beta=+60^{\circ}$. 
a barrier to the condensation, transfer coefficient. Therefore, the decrease in the wall temperature becomes larger compared to the saturation temperature. The maximum point for the heat transfer coefficient occurs in a region between $L=3 \mathrm{~m}$ and $L=5 \mathrm{~m}$, depending on the inclination angle and saturation temperature.

Another important matter is the fact that the condensation heat transfer coefficient at the entrance region of the tube is maximised for a saturation temperature of $70^{\circ} \mathrm{C}$, but it is minimised at the exit region. At the entrance region of the tube, the flow regime is almost annular owing to high steam velocities, ranging between 70 and $200 \mathrm{~m} / \mathrm{s}$, depending on the saturation temperature and the mass flow rate of the inlet steam. Therefore, the thermal conductivity of the liquid phase dominates in this region. As the thermal conductivity of the liquid phase increases with increases in the saturation temperature, the condensation heat transfer coefficient also increases. With the increase in the thickness of the liquid film due to the condensation along the tube and the effect of gravitation, the flow regime becomes stratified or stratified-wavy. Therefore, the convection through the liquid film is primarily responsible for the transfer of heat. The liquid density increases and its viscosity decreases when the saturation temperature increases. Therefore, the convection through the liquid film becomes less prominent, and as a result, the condensation heat transfer coefficient decreases.

Fig. 5 shows the effect of the saturation temperature on the vapour volume fraction for $\beta=0, \mathrm{G}=6.6 \mathrm{~kg} / \mathrm{m}^{2} \mathrm{~s}$, and $q^{\prime \prime}=7 \mathrm{~kW} / \mathrm{m}^{2}$, at the exit region of the tube. The thickness of the liquid film is larger in the lower section of the tube owing to gravitation. As it can be seen, the thickness of the liquid film (red colour) increases with the increase in the 
saturation temperature. This, results in the increase of the heat resistance toward the vapour phase from the tube surface, which consequently causes a lower heat transfer coefficient. Moreover, owing to the effect of the surface tension force, the liquid film stretches upwards at the two sides of the tube.

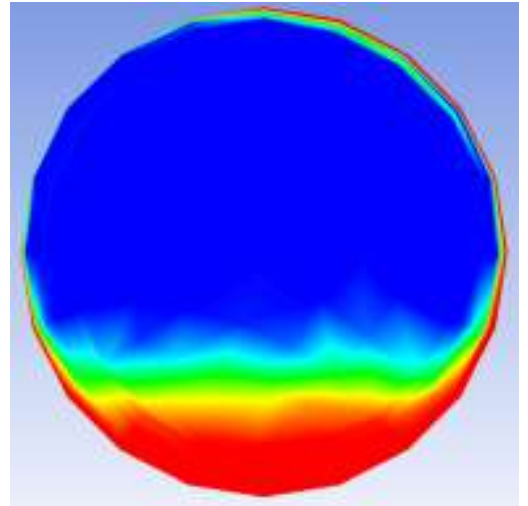

(a)

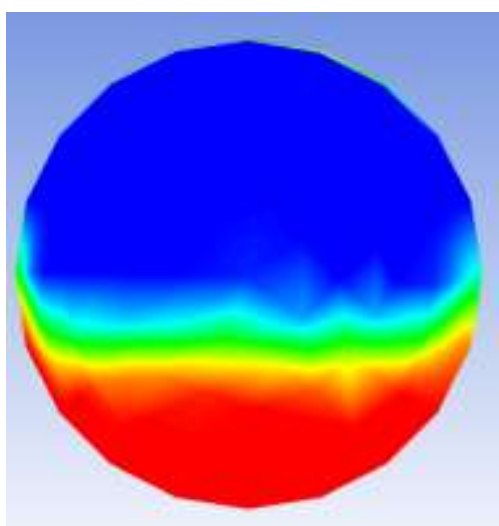

(c)

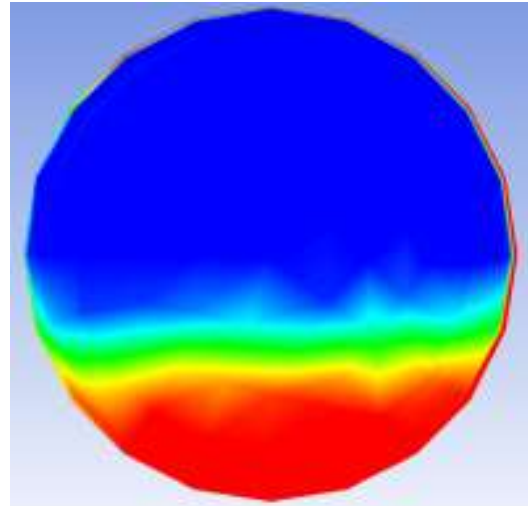

(b)

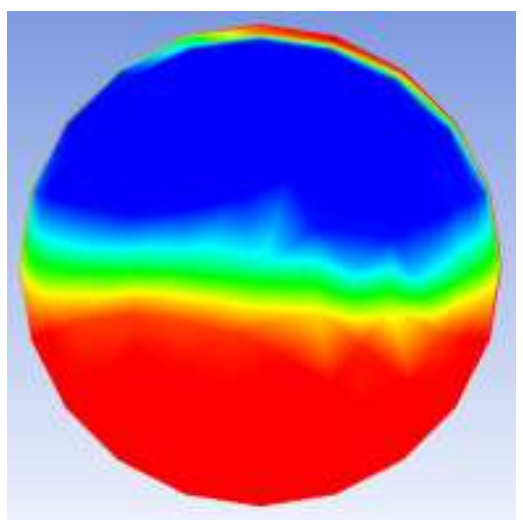

(d)

Fig. 5. Effect of saturation temperature on the vapour volume fraction for $\beta=0^{\circ}, G=6.6 \mathrm{~kg} / \mathrm{m}^{2} \mathrm{~s}$, and $q^{\prime \prime}=$ $7 \mathrm{~kW} / \mathrm{m}^{2}$. (a) $T_{\text {sat }}=40^{\circ} \mathrm{C}$, (b) $T_{\text {sat }}=50^{\circ} \mathrm{C}$, (c) $T_{\text {sat }}=60^{\circ} \mathrm{C}$, and (d) $T_{\text {sat }}=70^{\circ} \mathrm{C}$.

Fig. 6 depicts the circumferential wall temperature distribution at the exit region of the tube at $\mathrm{G}=6.6 \mathrm{~kg} / \mathrm{m}^{2} \mathrm{~s}, \beta=0$, and $q^{\prime \prime}=7 \mathrm{~kW} / \mathrm{m}^{2}$, for different saturation temperatures. The wall temperatures are 3 to $4{ }^{\circ} \mathrm{C}$ below the saturation temperature for all cases except for the region near the bottom side of the tube. This is because the lower side of the tube is covered by the condensate. 


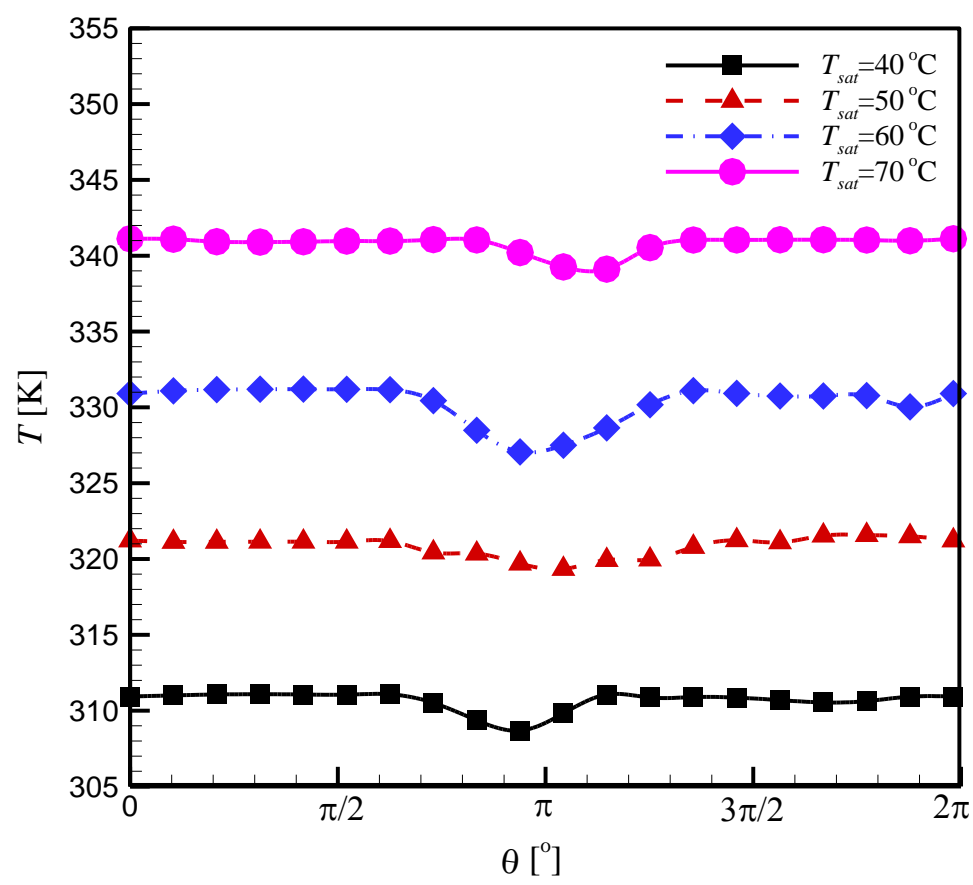

Fig. 6. Effect of saturation temperature on the temperatures of the tube wall at the exit region for $G=6.6$ $\mathrm{kg} / \mathrm{m}^{2} \mathrm{~s}, \beta=0^{\circ}$, and $q^{\prime \prime}=7 \mathrm{~kW} / \mathrm{m}^{2}$.

Fig. 7 shows the effect of the saturation temperature and inclination angle of the tube on the frictional pressure drop along the tube for $G=6.6 \mathrm{~kg} / \mathrm{m}^{2} \mathrm{~s}$ and $q^{\prime \prime}=7 \mathrm{~kW} / \mathrm{m}^{2}$. The frictional pressure drop along the tube decreases with increases of the saturation temperature. This is due to the fact that upon increases in the saturation temperature, the kinematic viscosities of both liquid and vapour phase decrease. It can also be seen that the increase is more considerable at lower saturation temperatures. Furthermore, the plots show that the frictional pressure drop decreases with increases in the inclination angle of the tube from the downward to the upward direction. 


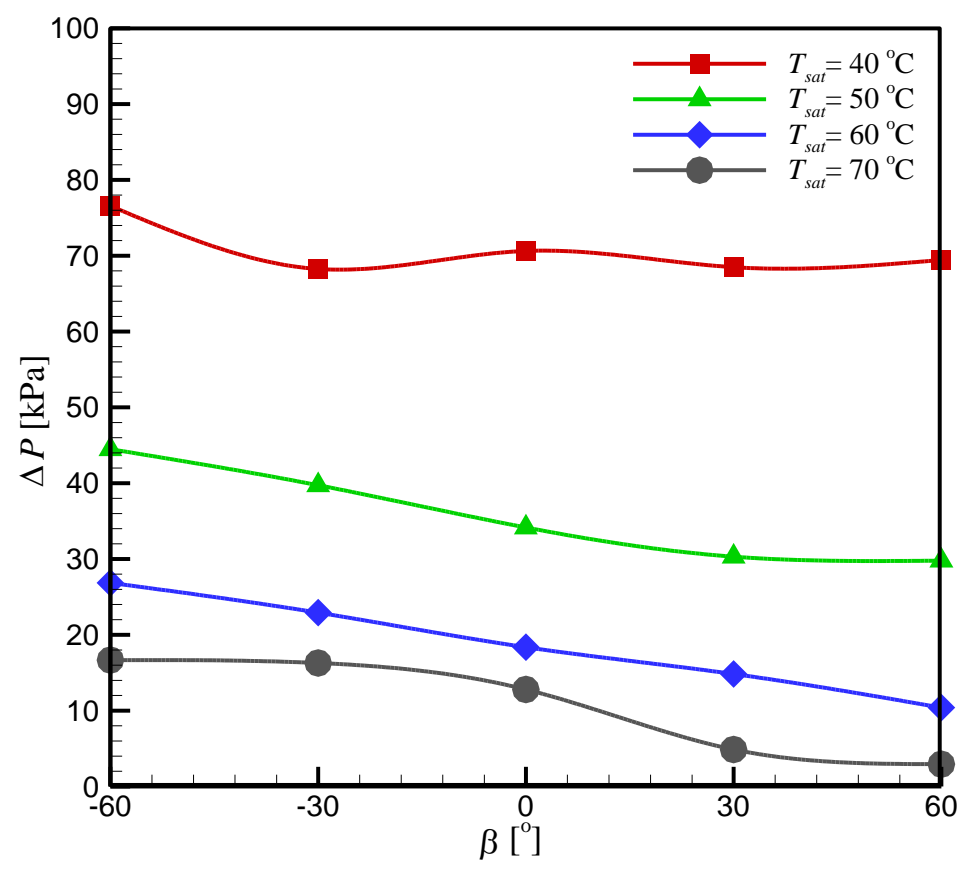

Fig. 7. Effect of saturation temperature on the pressure drop along the tube at different inclination angles for $G=6.6 \mathrm{~kg} / \mathrm{m}^{2} \mathrm{~s}$ and $q^{\prime \prime}=7 \mathrm{~kW} / \mathrm{m}^{2}$.

\subsection{Effect of inclination angle}

Fig. 8 presents the effect of tube inclination on the condensation heat transfer coefficient along the tube for $G=6.6 \mathrm{~kg} / \mathrm{m}^{2} \mathrm{~s}$ and $q^{\prime \prime}=7 \mathrm{~kW} / \mathrm{m}^{2}$, at different saturation temperatures. The plots show lack of specific trends in the variations of the condensation heat transfer coefficients along the tube, and with respect to the inclination angle of the tube. The simulated results are compatible with the experimental data of Wang and $\mathrm{Du}$ [18], in which they concluded that there was no particular trend for the variations in the condensation heat transfer coefficients of steam at a specific tube inclination angle, which ensured that the flow regime was almost stratified. 


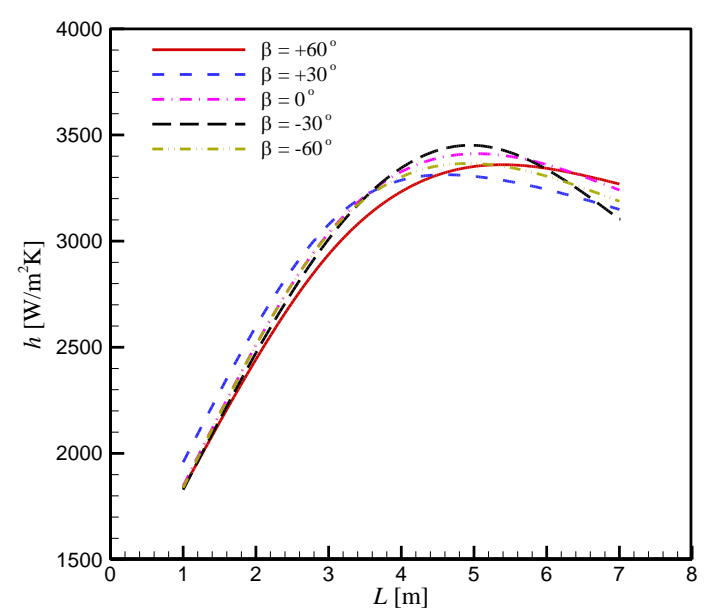

(a)

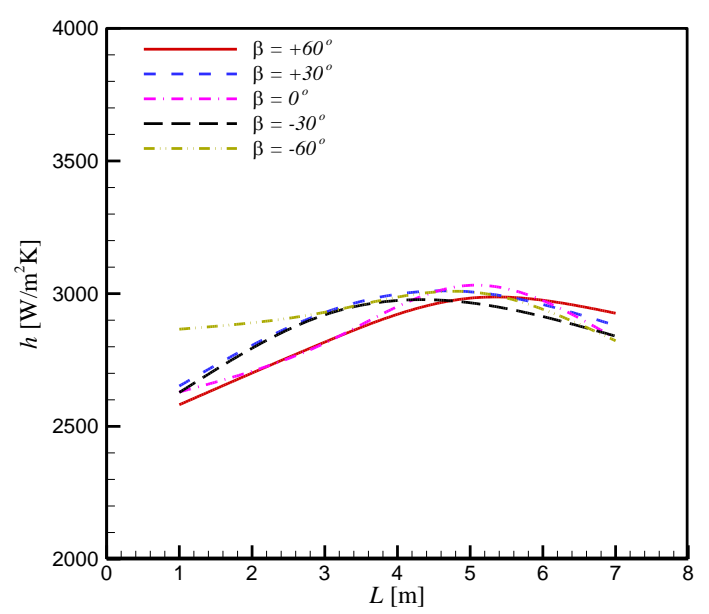

(c)

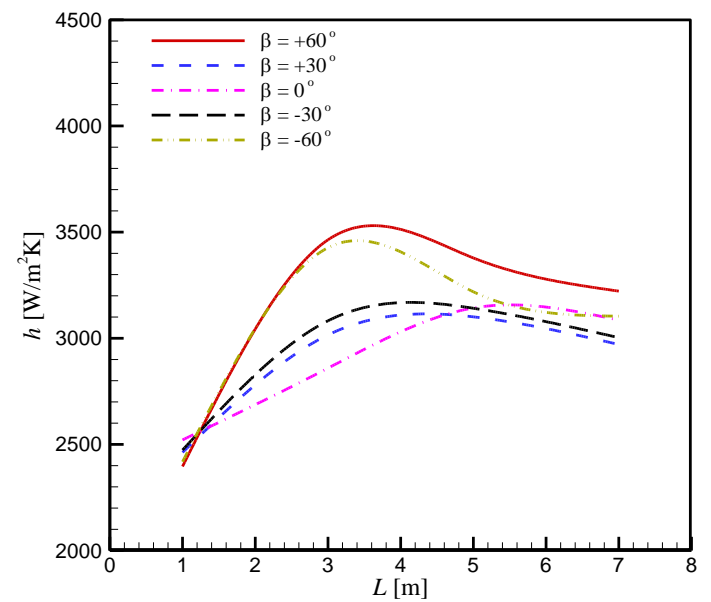

(b)



(d)

Fig. 8. Effect of tube inclination angle on the heat transfer coefficient along the tube for $G=6.6 \mathrm{~kg} / \mathrm{m}^{2} \mathrm{~s}$ and $q^{\prime \prime}=7 \mathrm{~kW} / \mathrm{m}^{2}$. (a) $T_{\text {sat }}=40^{\circ} \mathrm{C}$, (b) $T_{\text {sat }}=50^{\circ} \mathrm{C}$, (c) $T_{\text {sat }}=60^{\circ} \mathrm{C}$, and (d) $T_{\text {sat }}=70^{\circ} \mathrm{C}$.

Fig. 9 shows the effect of the inclination angle of the tube on the circumferential tube wall temperature at the exit region for $G=6.6 \mathrm{~kg} / \mathrm{m}^{2} \mathrm{~s}, T_{\text {sat }}=70^{\circ} \mathrm{C}$, and $q^{\prime \prime}=7 \mathrm{~kW} / \mathrm{m}^{2}$. The wall temperature of the tube is almost three degrees lower than the saturation temperature except for the region near the bottom of the tube where there was liquid phase accumulation. In this region, liquid film thickness acts as a barrier towards the 
transfer of heat and condensation, which leads to lower temperatures compared those attained at the top regions of the tube.

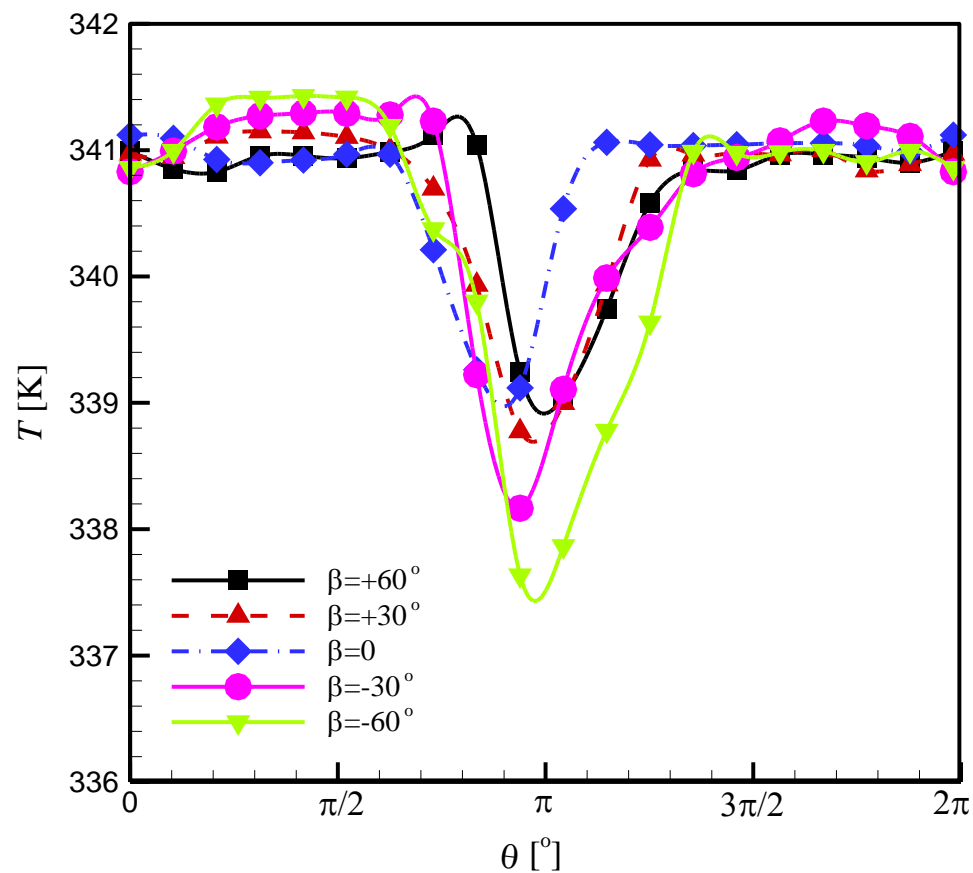

Fig. 9. Effect of tube inclination angle on the temperatures of the circumferential parts of the tube wall at the exit region for $G=6.6 \mathrm{~kg} / \mathrm{m}^{2} \mathrm{~s}, T_{\text {sat }}=70^{\circ} \mathrm{C}$, and $q^{\prime \prime}=7 \mathrm{~kW} / \mathrm{m}^{2}$.

\subsection{Effect of steam mass flow rate}

Fig. 10 shows the effect of steam mass flow rate on the heat transfer coefficient along the tube length for $q^{\prime \prime}=7 \mathrm{~kW} / \mathrm{m}^{2}$ and $\beta=0$. The increase in the flow rate of the steam mass resulted in the increase in the condensation heat transfer coefficient for both saturation temperatures of $40^{\circ} \mathrm{C}$ and $60^{\circ} \mathrm{C}$. The trends for variations in the condensation heat transfer coefficient with respect to the steam mass flow rate are almost the same except for the case of $G=4.4 \mathrm{~kg} / \mathrm{m}^{2} \mathrm{~s}$ and $T_{\text {sat }}=60^{\circ} \mathrm{C}$. With the increase in the saturation temperature, the density of the steam increases, and as a result, its velocity decreases inside the tube. Therefore, at a low mass flux of $G=4.4 \mathrm{~kg} / \mathrm{m}^{2} \mathrm{~s}$, the 
steam is condensed almost totally at the exit region of the tube, and the condensation heat transfer coefficient dramatically decreases.

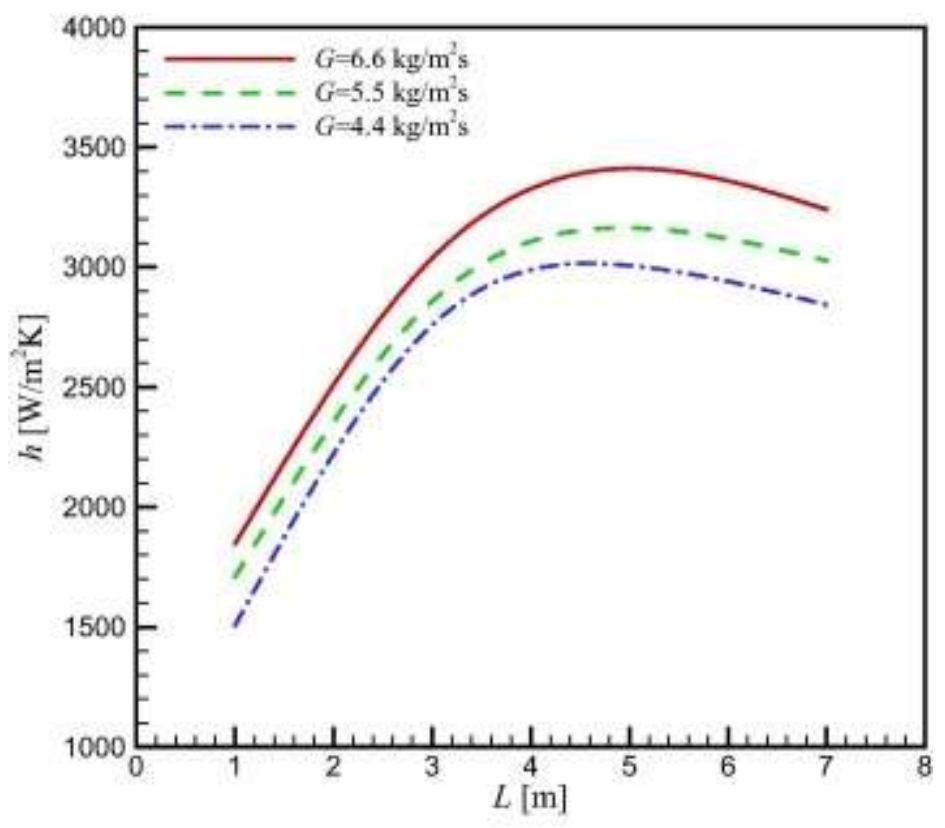

(a)

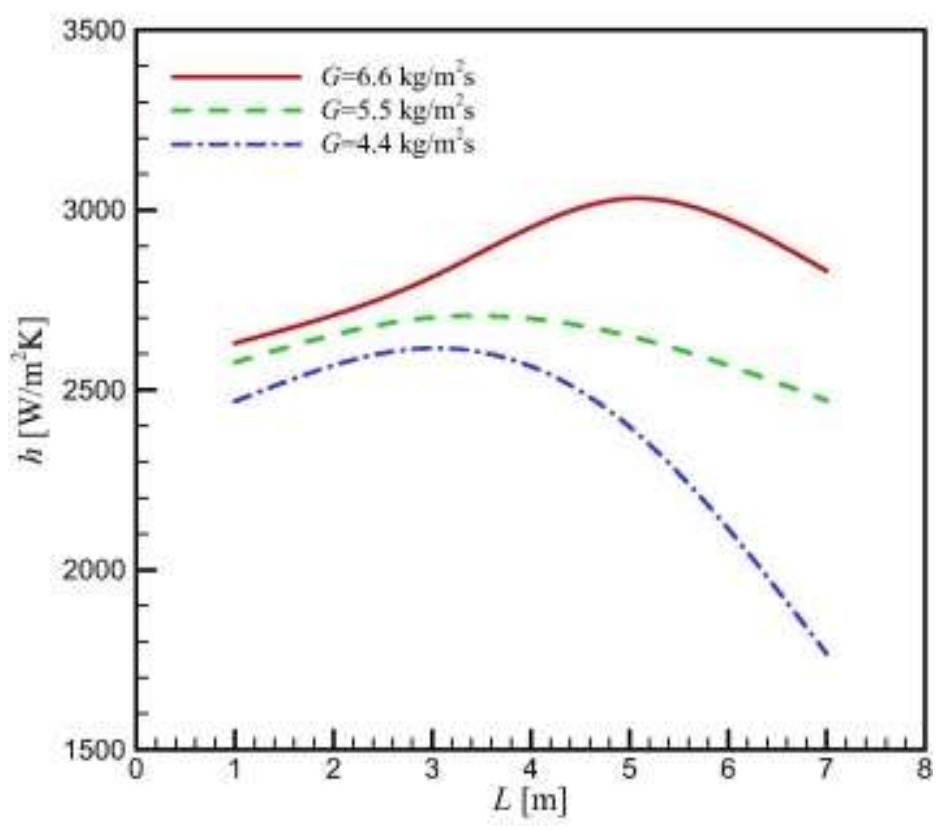

(b)

Fig. 10. Effect of steam mass flow rate on the heat transfer coefficient along the tube length for $q^{\prime \prime}=7$ $\mathrm{kW} / \mathrm{m}^{2}$ and $\beta=0$. (a) $T_{\text {sat }}=40^{\circ} \mathrm{C}$, and (b) $T_{\text {sat }}=60^{\circ} \mathrm{C}$. 
Fig. 11 illustrates the effect of steam mass flow rate on the pressure drop along the tube length for $q^{\prime \prime}=7 \mathrm{~kW} / \mathrm{m}^{2}, \beta=0$, and at different saturation temperatures. As expected, the pressure drop along the tube increases with steam mass flow rate increases owing to convection increases. Another important point is the fact that with increases of the saturation temperature, the kinematic viscosities of both the liquid and vapour phases decrease. Moreover, the decrease in the pressure drop with respect to the saturation temperature is more prominent at lower saturation temperatures.

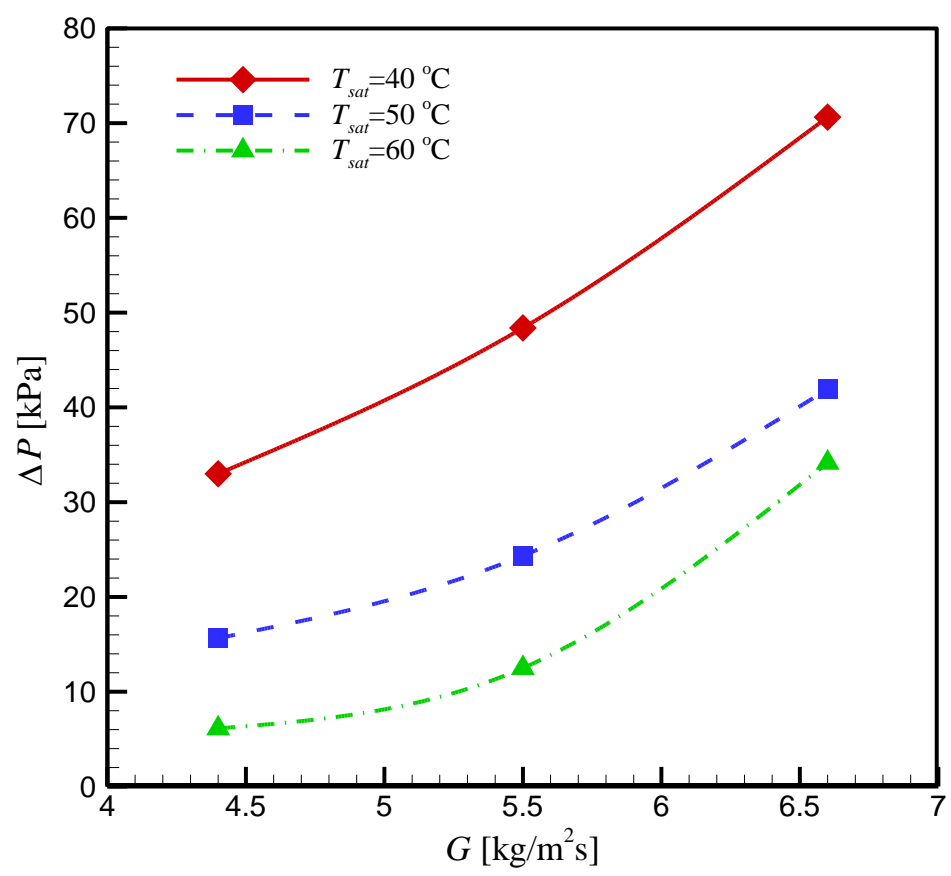

Fig. 11. Effect of steam mass flow rate on the pressure drop along the tube length for $q^{\prime \prime}=7 \mathrm{~kW} / \mathrm{m}^{2}$ and $\beta$ $=0^{\circ}$.

\subsection{Effect of wall heat flux}

Fig. 12 shows the effect of the tube wall heat flux on the heat transfer coefficient along the tube length for $G=6.6 \mathrm{~kg} / \mathrm{m}^{2} \mathrm{~s}$ and $\beta=0$, and for (a) $T_{\text {sat }}=40^{\circ} \mathrm{C}$, and (b) $T_{\text {sat }}=60^{\circ} \mathrm{C}$. The plots show that the condensation heat transfer coefficient increases with increases in the wall heat flux, which causes increases in the condensation rate. Another issue is 
that increases in the wall heat flux lead to the maximisation of the condensation heat transfer coefficient at lower values of $L$. This is due to the fact that with increases in the wall heat flux, the condensation rate and the produced liquid phase increase.

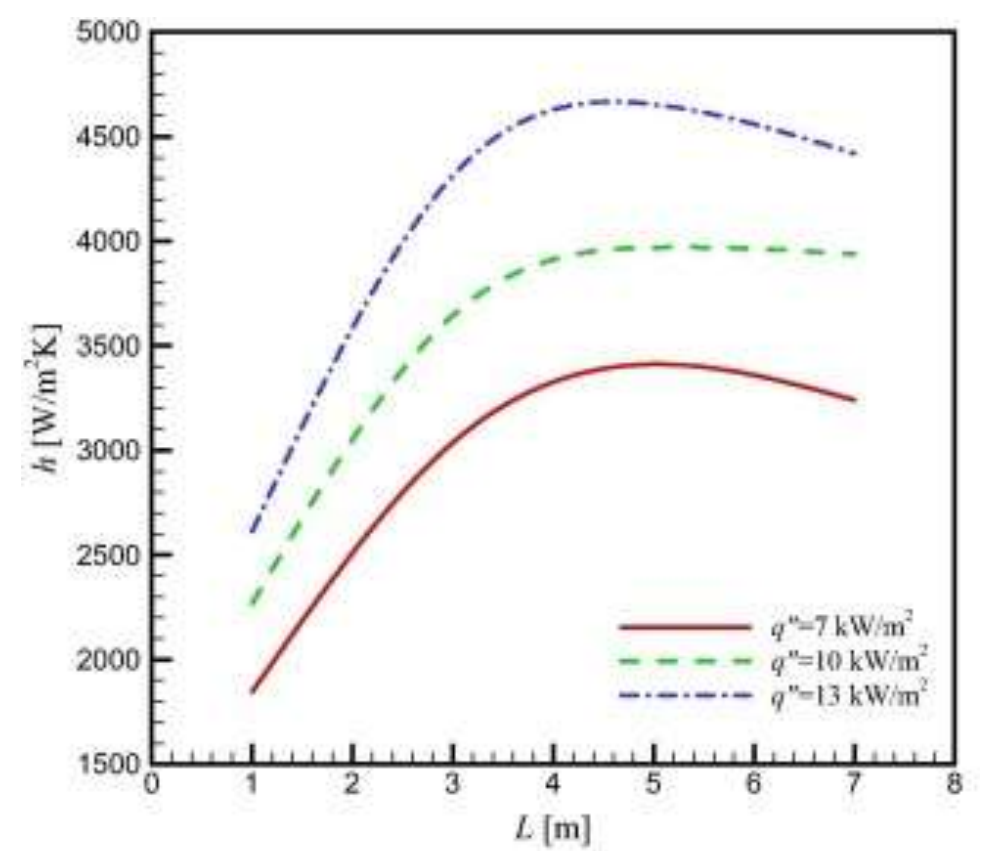

(a)

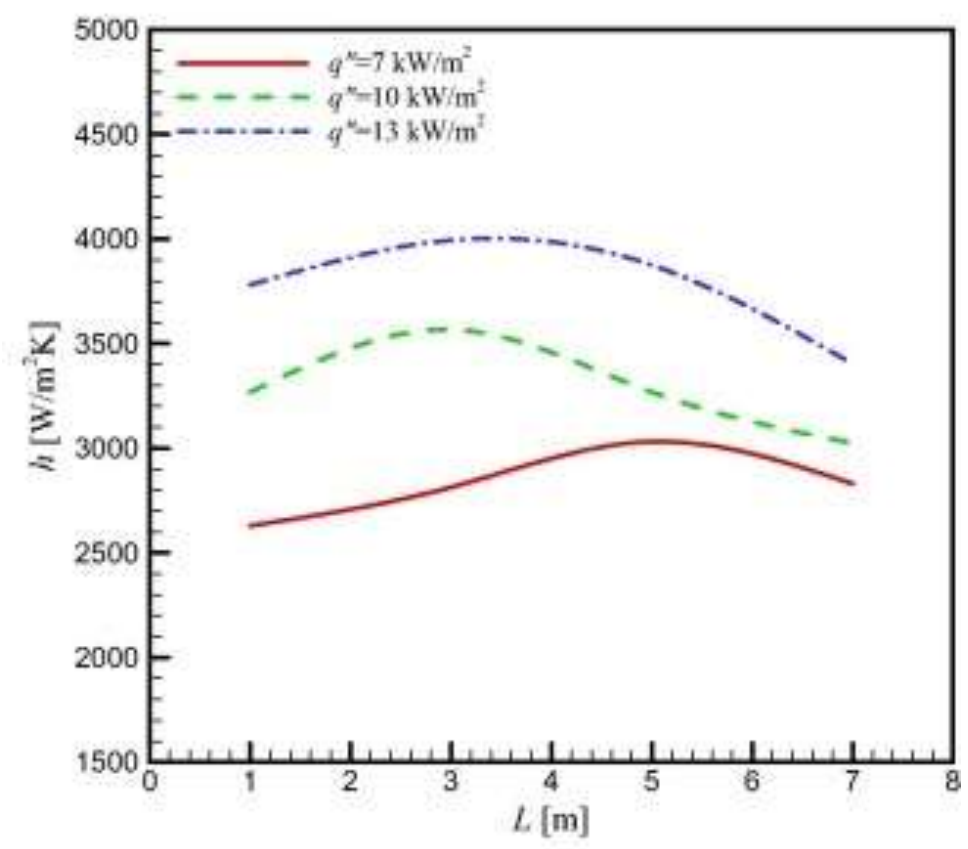

(b)

Fig. 12. Effect of tube wall heat flux on the heat transfer coefficient along the tube length for $G=6.6$ $\mathrm{kg} / \mathrm{m}^{2} \mathrm{~s}$ and $\beta=0^{\circ}$. (a) $T_{\text {sat }}=40^{\circ} \mathrm{C}$, and (b) $T_{\text {sat }}=60^{\circ} \mathrm{C}$. 
Fig. 13 shows the effect of the heat flux of the tube wall on the pressure drop along the tube length for $G=6.6 \mathrm{~kg} / \mathrm{m}^{2} \mathrm{~s}$ and $\beta=0$. As discussed before, the pressure drop decreased along the tube when the saturation temperature increased. This decrease in the pressure drop is more significant at lower saturation temperatures. Moreover, with increases in the heat flux of the wall, the pressure drop along the tube increases because of the increase in the condensation rate and turbulence along the tube. The changes in the pressure drop became less considerable at higher heat fluxes. This is due to the fact that at higher values of the wall heat flux, the tube is almost filled with liquid. Further increases in the wall heat flux will not change the condensation rate significantly.

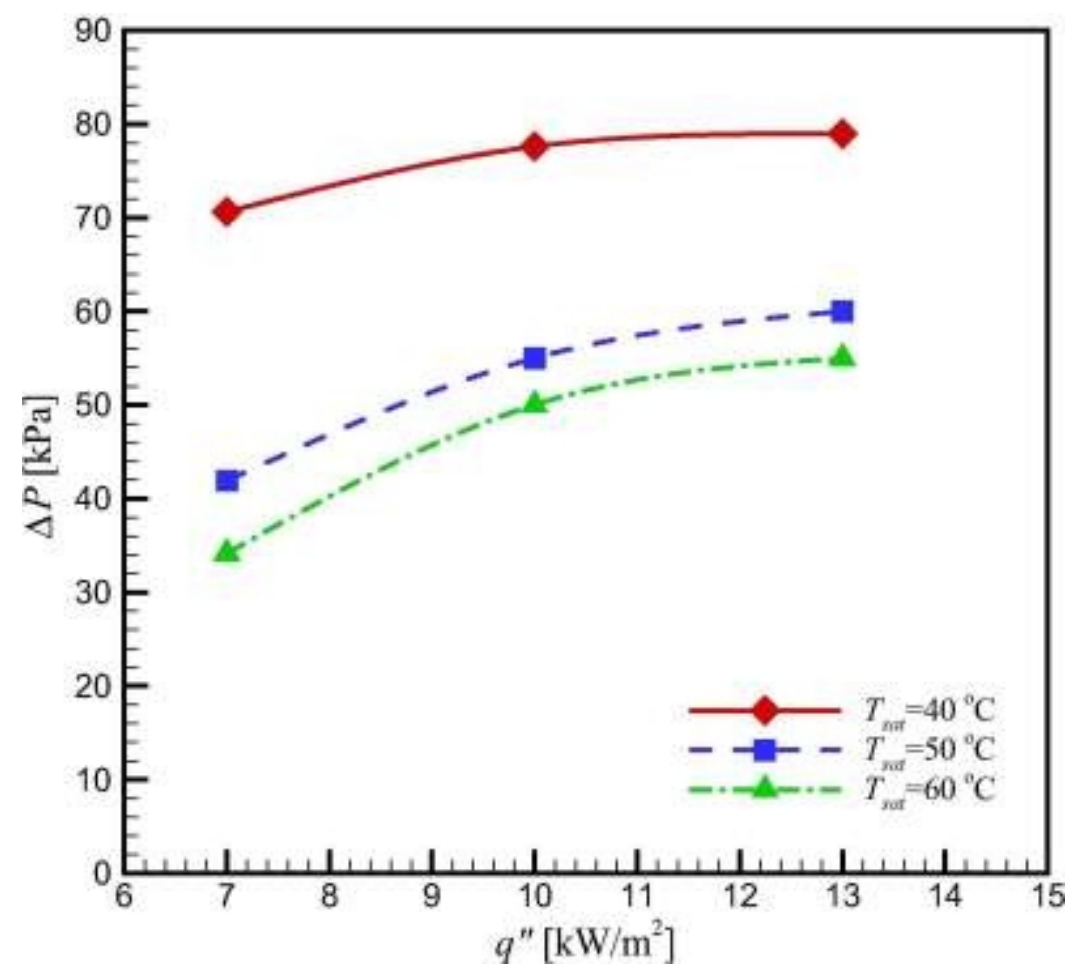

Fig. 13. Effect of the heat flux of the tube wall on the pressure drop along the tube length for $G=6.6$ $\mathrm{kg} / \mathrm{m}^{2} \mathrm{~s}$ and $\beta=0^{\circ}$.

\section{Conclusion}

In this work, numerical simulations were performed for the estimation of steam condensation inside a long and smooth tube. The effects of various parameters, such as 
the steam saturation temperature, mass flux, and tube orientation, on the condensation heat transfer coefficient and the pressure drop along the tube, were investigated. The results showed excellent agreement between the simulated and the available experimental data. Based on the numerical simulations, the following conclusions can be drawn:

I. The condensation heat transfer coefficient first increased and then decreased along the tube length.

II. The condensation heat transfer coefficients were larger for higher saturation temperatures at the entrance region, and became gradually smaller along the tube length.

III. The pressure drop and condensation heat transfer coefficient decreased as the saturation temperature increased.

IV. The results did not show a clear trend for the effect of the inclination angle on the condensation heat transfer coefficient. These results were compatible with previous experimental results obtained by Wang and Du [18].

V. The simulation results also showed that the condensation heat transfer coefficient increased with increases in the wall heat flux and steam mass flux of the tube.

VI. The plots of the circumferential temperature distributions over the tube wall showed that the temperature at the bottom of the tube was the lowest, owing to the highest thickness of the liquid film deposited in this region. 


\section{References}

[1] L. Liebenberg, J. p. Meyer, A review of flow pattern-based predictive correlations during refrigerant condensation in horizontally smooth and enhanced tubes, Heat Transf. Eng. 29 (2008) 3-19.

[2] A. Cavallini, J. S. Brown, D. Del Col, C. Zilio, In-tube condensation performance of refrigerants considering penalization terms (energy losses) for heat transfer and pressure drop, Int. J. Heat Mass Transf. 53 (2010) 2885-2896.

[3] M. B. Ould Didi, N. Kattan, J. R. Thome, Prediction of two-phase pressure gradients of refrigerants in horizontal tubes, Int. J. Refrig. 25 (2002) 935-947.

[4] A. Miyara, Condensation of hydrocarbons - a review, Int. J. Refrig. 31 (2008) 621632.

[5] A. S. Dalkilic, S. Wongwise, Intensive literature review of condensation inside smooth and enhanced tubes, Int. J. Heat Mass Transf. 52 (2009) 3409-3426.

[6] S. P. Olivier, J. P. Meyer, M. D. Paepe, K. D. Kerpel, The influence of inclination angle on void fraction and heat transfer during condensation inside a smooth tube, Int. J. Multi. Flow 80 (2016) 1-14.

[7] S. Lips, J. P. Meyer, Two-phase flow in inclined tubes with specific reference to condensation: A review, Int. J. Multi. Flow 37 (2011) 845-859.

[8] S. G. Mohseni, M. A. Akhavan-Behabadi, M. Saeedinia, Flow pattern visualization and heat transfer characteristics of R-134a during condensation inside a smooth tube with different tube inclinations, Int. J. Heat Mass Transf. 60 (2013) 598-602.

[9] S. A. Nada, H. M. S. Hussein, General semi-empirical correlation for condensation of vapour on tubes at different orientations, Int. J. Therm. Sci. 100 (2016) 391-400. 
[10] S. Lips, J. P. Meyer, Experimental study of convective condensation in an inclined smooth tube. Part I: Inclination effect on flow pattern and heat transfer coefficient, Int. J. Heat Mass Transf. 55 (2012) 395-404.

[11] S. Lips, J. P. Meyer, Experimental study of convective condensation in an inclined smooth tube. Part II: Inclination effect on pressure drops and void fractions, Int. J. Heat Mass Transf., 55 (2012) 405-412.

[12] S. Lips, J. P. Meyer, Effect of gravity forces on heat transfer and pressure drop during condensation of R134a, Microgravity Sci. Technol. 24 (2012) 157-164.

[13] S. Lips, J. P. Meyer, Stratified flow model for convective condensation in an inclined tube, Int. J. Heat Fluid Flow 36 (2012) 83-91.

[14] J. Xu, Y. Wu, Z. Shi, L. Lao, D. Li, Studies on two-phase co-current air/nonNewtonian shear-thinning fluid flows in inclined smooth pipes, Int. J. Multi. Flow, 33 (2007) 948-969.

[15] M. M. Shah, Prediction of heat transfer during condensation in inclined plain tubes, Appl. Therm. Eng. 94 (2016) 82-89.

[16] G. Caruso, D. Maio, A. Naviglio, Film condensation in inclined tubes with noncondensable gases: An experimental study on the local heat transfer coefficient, Int. Commun. Heat Mass Transf. 45 (2013) 1-10.

[17] Y. Wang, X. Mu, S. Shen, W. Zhang, Heat transfer characteristics of steam condensation flow in vacuum horizontal tube, Int. J. Heat Mass Transf. 108 (2017) 128-135.

[18] B. Wang, X. Du, Study on laminar film-wise condensation for vapour flow in an inclined small/mini-diameter tube, Int. J. Heat Mass Transf. 43 (2000) 18591868. 
[19] T. Wu, K. Vierow, Local heat transfer measurements of steam/air mixtures in horizontal condenser tubes, Int. J. Heat Mass Transf. 49 (2006) 2491-2501.

[20] G. Caruso, D. Vitale di Maio, A. Naviglio, Condensation heat transfer coefficient with non-condensable gases inside near horizontal tubes, Desalination, 309 (2013) 247-253.

[21] M. Punetha, S. Khandekar, A CFD based modelling approach for predicting steam condensation in the presence of non-condensable gases, Nuc. Eng. Des. 1 (2017) 280-296.

[22] G. Zschaeck, T. Frank, A. D. Burns, CFD modelling and Validation of wall condensation in the presence of non-condensable gases, Nuc. Eng. Des. 279 (2014) 137-146.

[23] L. Vyskocil, J. Schmid, J. Macek, CFD simulation of air-steam flow with condensation, Nuc. Eng. Des. 279 (2014) 147-157.

[24] B. Ren, L. Zhang, H. Xu, J. Cao, Z. Tao, Experimental study on condensation of steam/air mixture in a horizontal tube, Exp. Therm. Fluid Sci. 58 (2014) 145155.

[25] J. C. Chato, Laminar condensation inside horizontal and inclined tubes, Am. Soc. Heat. Refrig. Air Cond. Eng. (ASHRAE) 4 (1962) 52-60.

[26] R. Würfel, T. Kreutzer, W. Fratzscher, Turbulence transfer processes in adiabatic and condensing film flow in an inclined tube, Chem. Eng. Technol. 26 (2003) $439-448$.

[27] F. T. Kanizawa, G. Ribatski, Void fraction and pressure drop during external upward two-phase crossflow in tube bundles - part I: Experimental investigation, Int. J. Heat Fluid Flow 65 (2017) 200-209. 
[28] P. Benli, L. Zhong, X. Wei, W. Rongfu, M. Xuehu, M. Jiaxuan, L. Chen, A numerical study of droplet motion/departure on condensation of mixture vapour using lattice Boltzmann method, Int. J. Heat Fluid Flow 68 (2017) 53-62.

[29] C. W. Hirt, B. D. Nichols, Volume of fluid (VOF) method for the dynamics of free boundaries. J. Comput. Phys. 39 (1981) 201-225.

[30] J. U. Brackbill, D. B. Kothe, C. Zemach, A continuum method for modeling surface tension, Comput. Phys. 100 (1992) 335-354.

[31] Z. Yang, T. H. Shih, New time scale based $k-\varepsilon$ model for near wall turbulence. AIAA J., 317 (1993) 1191-1197.

[32] W. H. Lee, A pressure iteration scheme for two-phase flow modeling, multiphase transport: fundamentals, reactor safety, applications, Verizoglu, T. N., ed., Hemisphere Publishing, Washington, DC, 1980.

[33] Z. Liu, B. Sunden, J. Yuan, VOF modeling and analysis of film wise condensation between vertical parallel plates, Heat Transf. Res. 43 (2012) 47-68.

[34] S. C. K. De Schepper, G. J. Heynderichx, G. B. Marin, Modeling the evaporation of a hydrocarbon feedstock in the convection section of a steam cracker, Comp. Chem. Eng. 33 (2009) 122-132.

[35] S. M. A. Noori Rahim Abadi, J. P. Meyer, Numerical investigation into the inclination effect on conjugate pool boiling and the condensation of steam in a passive heat removal system, Int. J. Heat Mass Transf. 122 (2018) 1366-1382.

[36] M. Bahreini, A. Ramiar, , A. A. Ranjbar, Numerical simulation of bubble behaviour in subcooled flow boiling under velocity and temperature gradient, Nucl. Eng. Des. 293 (2015) 238-248. 
[37] S. M. A. Noori Rahim Abadi, J. P. Meyer, J. Dirker, Numerical simulation of condensation inside an inclined smooth tube, Chem. Eng. Sci. 182 (2018) 132145.

[38] S. M. A. Noori Rahim Abadi, Josua P. Meyer, J. Dirker, Effect of inclination angle on the condensation of R134a inside inclined smooth tube, Chem. Eng. Res. Des. 132 (2018) 346-357.

[39] N.B. Vargaftik, Handbook of Physical Properties of Liquids and Gases, Hemisphere, New York, NY, 1975.

[40] J. Barber, D. Brutin, K. Sefiane, L. Tadrist, Bubble confinement in flow boiling of FC72 in a rectangular microchannel of high aspect ratio, Exp. Therm. Fluid Sci. 34 (2010) 1375-1388.

[41] M. Rudman, Volume-tracking methods for interfacial flow calculations, Int. J. Numer. Methods Fluids 24 (1997) 671-691. 